\title{
The Need for Recovering the Subjugated Knowledge of Traditional Chinese Medicine
}

\author{
Lau Kin $\mathrm{Chi}^{1}$ · Sit Tsui ${ }^{2}$ \\ Published online: 30 November 2020 \\ (c) Society for International Development 2020, corrected publication 2020
}

\begin{abstract}
This short article will explore the question of COVID-19 vaccine as a global public good, and examine the potential of Traditional Chinese Medicine in offering alternative therapy for the most vulnerable populations in the Global South.
\end{abstract}

Keywords COVID-19 vaccine - Global public good - Universal access to health care - Supremacy of western medicine Science versus culture

In the midst of the ever-deteriorating spread of COVID-19, a race has been run to develop vaccines which appear to be the hope for the desperate situation. Russia announced on 11 August 2020 that it registered the world's first coronavirus vaccine, and this piece of news was received with applause by some and skepticism from others that doubted if Russia had skipped the routine three phases for validation of a vaccine. At the same time, whether the supposedly more 'reliable' pharmaceutical corporations of the developed West had fully complied with the procedures, which normally would take two to three years, cannot be ascertained. Besides the question of safety and efficacy of the vaccines, other questions as crucial are foregrounded, including the question of whether they would be affordable and accessible for the populous populations of the Global South. The staggering increase in the figures (over 30 million confirmed cases and 1 million deaths) showing no sign of abating, the 'herd immunity' scenario is nightmarish, for the term, positively referring to 'immunity', could have been termed 'herd extinction' (if half the herd goes extinct and half develops

The original online version of this article was revised due to an unfortunate oversight the correspondence author has been given incorrectly.

Sit Tsui

sittsui@gmail.com

Lau Kin Chi

laukc@ln.edu.hk

1 Lingnan University, Hong Kong, China

2 Southwest University, Chongqing, China immunity, both terms could be as valid). It accepts, involuntarily and helplessly, a scenario of tens or hundreds of millions to die before some fortunate ones may survive.

\section{COVID-19 Vaccines as a 'Global Public Good'}

In the race in producing vaccines, according to $\mathrm{WHO}$, there are currently over 169 COVID-19 vaccine candidates under development, with 26 in the human trial phase. ${ }^{1}$ On 4 May 2020, the leaders of France, Germany, Italy and Norway and senior European Union officials pledged to raise 7.5 billion euros to help find a vaccine and treatments for COVID-19 as part of an 'international alliance' fighting the disease. They wrote: 'If we can develop a vaccine that is produced by the world, for the whole world, this will be a unique global public good of the twenty-first century'. Responding to the global challenge requires 'bringing together the world's best-and most prepared-minds to find the vaccines, treatments and therapies we need to make our world healthy again... Guided by the sustainable development goals, we can redesign the power of community, society and global collaboration, to make sure that nobody is left behind. ${ }^{2}$

Chinese President Xi Jinping, in a speech to the World Health Assembly on 18 May 2020, announced that 'COVID19 vaccine development and deployment in China, when

\footnotetext{
1 https://www.who.int/emergencies/diseases/novel-coronavirus-2019/ COVID-19-vaccines gclid=EAIaIQobChMIooKLvOLo6wIVS a6WCh32-AviEAAYASAAEgKlwvD_BwE.

2 https://www.theguardian.com/world/2020/may/03/european-leade rs-join-forces-to-combat-COVID-19.
} 
available, will be made a global public good, which will be China's contribution to ensuring vaccine accessibility and affordability in developing countries.' China would also provide USD 2 billion over two years to support the WHO's fight against the pandemic.

Vaccines and treatments being designated as a 'global public good' is certainly welcome to the Global South. However, what does this mean? 'Public' means this is not private, and hence it is provided for or sponsored by the government or non-private sectors. 'Global' means this is not just a 'national' good. There are cautions against 'vaccine nationalism', referring to bilateral agreements between countries and drug companies. ${ }^{3}$ On 14 May, when Paul Hudson, CEO of the French giant drug maker Sanofi, said that the US had the right to the largest pre-order of coronavirus vaccine due to research funding, French President Emmanuel Macron was outraged and said a vaccine against COVID-19 must be a 'common good' that stands 'outside of market rules'. ${ }^{4}$ Outside market rules because the French drug maker should not prioritize the US that gave the funds, but was it implicit that French drug maker should prioritize French interests? Pannier-Runacher, a French government official, said, 'the vaccine would be available to all countries, including France, especially because the company has production capacity there'. Hence, in the fight for access to the vaccine, 'equitable and universal access' may just be rhetorical, and terms like 'global public good' or 'common good' need to be substantiated.

Obviously, the coronavirus has crossed all borders, thanks to globalization-travel of people and goods to all corners of the world. The coronavirus poses a threat to the poor in particular, but not only the poor, as the rich and the elite, despite being much better protected, cannot fully insulate themselves from coronavirus possibly carried by their cook, driver, cleaner, courier man..., on the food packaging, or in public places. There are certainly different degrees of exposure and vulnerability, but technically speaking, no one on earth is exempt as we are social beings, and being social, we come into contact with others.

This understanding is nothing profound, it is common sense. Hence the European leaders saw the need 'to make sure that nobody is left behind', and President Xi showed concern for 'ensuring vaccine accessibility and affordability in developing countries'. However, not only will we have to wait and see how such moves and gestures translate into the reality, we also need to ask: does the designation of COVID-19 vaccine as a global public good change its character as a 'commodity', that is, not only for its use value, but

\footnotetext{
3 https://www.scmp.com/news/china/society/article/3090460/coron avirus-will-vaccine-deals-lead-poorer-countries-missing-out.

${ }^{4}$ https://www.bloomberg.com/news/articles/2020-05-14/france-saysunacceptable-for-u-s-to-get-sanofi-vaccine-first.
}

also its exchange value? How will 'patents' work, and how will profits of pharmaceutical corporations be controlled or monitored? On 22 September 2020, WHO anticipated that 2 billion vaccine doses might be available by the end of 2021, but Tedros Adhanom, Director-General of WHO, added: 'We sink or swim together', and the fastest route to ending the pandemic is 'to ensure some people are vaccinated in all countries, not all people in some countries'. ${ }^{5}$ This plea reflects the grim reality for the countries representing $60 \%$ of the world population that had signed up to the WHO COVAX scheme to buy vaccines. In April 2020, the WHO, the European Commission and France launched the Access to COVID-19 Tools (ACT) Accelerator, which aimed to provide equitable access to COVID-19 diagnostics, treatments and vaccines. The COVAX focused on the latter. ${ }^{6}$ Major powers such as US, Russia, France and Germany were not part of this scheme as they had their own agreements with vaccine makers. China with a great vaccine production potential joined COVAX on 9 October $2020 .^{7}$ Yet, Tedros added another grim note: even if vaccines are available, whether the southern countries can afford them is a question.

From these developments and projections, we know that the vaccines, even if produced, will most likely have to be bought, and some countries in the north have an advantage of sponsoring drug companies and ensuring supply to their nationals. When Tedros made the plea 'to ensure some people are vaccinated in all countries, not all people in some countries', he anticipated the most unwanted but probable outcome. When his lobbying rationale was that this is 'the fastest route to ending the pandemic', he was referring to the route for the entire world population. 'We sink or swim together'! The question is, who is this 'we' inclusive of and exclusive of? The 'we', the world population that Tedros has in mind, might not be what national leaders have in mind, or what pharmaceutical CEOs have in mind.

\section{Saving Lives Versus Making War and Reaping Profits}

If we subscribe to the idea of making COVID-19 vaccines truly a global public good accessible to everyone on earth, can the whole world afford it in monetary terms? In the COVAX Facility scheme where self-financing countries can commit to purchase of the vaccines, down payment is USD 1.60 per dose, which is $15 \%$ of the total cost. ${ }^{8}$ This means

\footnotetext{
5 https://www.tvnz.co.nz/one-news/world/targets-2-billion-COVID -19-vaccine-doses-end-2021.

${ }^{6}$ https://www.gavi.org/vaccineswork/covax-explained.

7 https://www.scmp.com/news/china/science/article/3104877/covax -chinas-americas-out-what-it-all-about.

${ }^{8}$ https://www.gavi.org/vaccineswork/covax-explained.
} 
each vaccine dose is priced at USD10.60. If all 7.8 billion population on earth were to receive the vaccine on this price, how much would it cost? USD 82.68 billion.

Is this an astronomical figure? Let us compare this to other figures. In 2019, the total military spending of 15 countries amounted to USD 1,917 billion. ${ }^{9}$ Of this, the US military spending was $38 \%$. US estimated military spending from October 2020 to September 2021 is USD 934 billion, which is USD 2.559 billion per day. ${ }^{10}$ Please note, per day!

According to the FAO Report on Food Security and Nutrition around the World in 2020, 2 billion people from the Global South out of the 7.8 billion world population suffer from food insecurity (moderate and severe). Providing them with a healthy diet (the cost of the global average is USD 3.75 per day) costs USD 7.5 billion, which is three days of US military expenditure. ${ }^{11}$

If all 7.8 billion people on earth were to receive the COVID-19 vaccine, it would amount to 32 days of US military expenditure.

On 7 April 2020, PeaceWomen Across the Globe issued a statement on COVID-19 appealing to an immediate global ceasefire in all corners of the world, echoing the call from the UN Secretary António Guterres. ${ }^{12}$

Do we have the innocence to ask a question about the emperor's new clothes? Notwithstanding the rhetoric about universal human rights, when the material wealth on the planet could afford the entire human population with food, basic health care and a decent livelihood, when money is put not for creative and constructive use but on weapons of mass destruction (on the unjustifiable pretext of 'national defense'), should not the massive deaths from pandemics as well as from so-called 'curable diseases' be denounced as a crime against humanity?

The pandemic is a call for the world to not only make COVID-19 vaccines a global public good or common good, but also to instate universal access to healthcare. Health is a basic human right.

What can be the first steps towards this goal? The coronavirus taking so many human casualties was unthinkable a year ago. The solution needs to be bold and daring. In the Sanofi episode, French Prime Minister Edouard Philippe tweeted that 'equal access to a vaccine is not negotiable'. Olivier Faure, head of France's Socialist Party, suggested that Paris-based Sanofi risked being nationalized. ${ }^{13}$

\footnotetext{
9 https://www.sipri.org/sites/default/files/2020-04/fs_2020_04_milex _0_0.pdf.

10 https://www.thebalance.com/u-s-military-budget-components -challenges-growth-3306320.

11 http://www.fao.org/3/ca9692en/CA9692EN.pdf.

12 https://www.1000peacewomen.org/en/who-we-are/board/call-forimmediate-ceasefire-94.html

13 https://www.bloomberg.com/news/articles/2020-05-14/franc e-says-unacceptable-for-u-s-to-get-sanofi-vaccine-first.
}

Indeed, there is the thought for private drug makers to be nationalized for the national good. What could be the steps for drug makers to be 'globalized' - not in the sense of their being multinational, as many of them are already, but in the sense of the global production of necessary medicine for free, equitable, universal access?

On 14 May 2020, more than 140 world leaders, experts and elders made an unprecedented call for guarantees that COVID-19 vaccines, diagnostics, tests and treatments will be provided free of charge to everyone, everywhere. The statement demands that 'all vaccines, treatments and tests be patent-free, mass produced, distributed fairly and made available to all people, in all countries, free of charge'. This is the 'people's vaccine'. ${ }^{14}$ This is a most welcome initiative, provided it does not remain an empty call. Some steps have been taken when China announced to join the COVAX, but this is still far from adequate.

To realize it, pharmaceutical corporations from the Global North must be politically, ethically and economically challenged. How can there be the transition from profit-seeking vaccine production for only those who can afford it, to a people's vaccine which is patent free, non-profit seeking, and affordable to the Global South? What was the reaction of the pharmaceutical companies to these propositions? On 8 September 2020, nine big biopharma companies, i.e., AstraZeneca, BioNTech, GlaxoSmithKline, Johnson \& Johnson, Merck, Moderna, Novavax, Pfizer, and Sanofi, jointly proclaimed 'a united commitment to uphold the integrity of the scientific process as they work towards potential regulatory filings and approvals of the first COVID-19 vaccines'. ${ }^{15}$ Not mentioning the crucial question of patent right, pricing and beneficiaries, the statement stresses that they 'stand with science'-global regulatory filings and approvals. It mentions in general regulatory agencies in the world, but only one name is consistently mentioned: 'the United States Food and Drug Administration (FDA)'. Calling itself a 'historic pledge', the historicity is nothing more than the nine pharmaceutical corporations, previously rivals in business, now coming together for a united message and a united position. Indeed, they have found their common interest superseding their inter-rivalry. What then is the common rival they are together confronting? Could it be the threat of the implementation of the 'people's vaccine', or pharmaceutical producers outside of the Nine?

\footnotetext{
14 https://www.unaids.org/en/resources/presscentre/pressreleaseand statementarchive/2020/may/20200514_covid19-vaccine.

15 https://www.pfizer.com/news/press-release/press-release-detail/ biopharma-leaders-unite-stand-science.
} 


\section{Traditional Medicine as Alternative}

On 13 August 2020, news of a first documented case of a second infection and rapid mutation of the coronavirus was reported. ${ }^{16}$ On 9 September 2020, the final clinical trials for a coronavirus vaccine, developed by AstraZeneca and Oxford University, was put on hold briefly after a participant had a suspected adverse reaction in the UK. AstraZeneca described it as a 'routine' pause in the case of 'an unexplained illness' ${ }^{17}$ These dim hopes of vaccines catching up in the battle against the coronavirus.

A vaccine will not be a magic bullet, because it may be only about $50 \%$ effective, as warned by Anthony Fauci, chief of the National Institute of Health and Infectious Disease in the US. The FDA confirmed that once a vaccine is shown to be safe and at least $50 \%$ effective, it could be approved for use in the US. What does 50\% effective mean? This means that $50 \%$ of those getting a vaccine shot could still get sick, only 'hopefully' the symptoms will be milder, and not develop into severity or death. ${ }^{18}$ We are then led into the question: are COVID-19 vaccines the only rescue from the pandemic?

When the solution is either waiting for the vaccines, or watching people die like flies in the 'herd immunity' scheme, apparently no other alternatives are in sight. However, for the billions who will need to find a way to survive, is there indeed no alternative?

China has, compared to the USA, Brazil or India, effectively contained the pandemic spread as well as its casualties. One major factor is the preventive measures of wearing masks, washing hands, and practicing isolation. Despite the privatization of hospitals and health care for over two decades, there are institutional mechanisms and popular mobilization that contribute to the efforts to fight the pandemic. What has also drawn attention is the widespread use of Traditional Chinese Medicine (TCM) based on traditional wisdoms and practices, popular reception, and inexpensive local herbs.

On 25 March 2020, the State Council Information Office of China presented the important role of TCM and a list of effective drugs in COVID-19 prevention and control, and reported that a total of 74,187 COVID-19 patients, or $91.5 \%$ of the then total confirmed cases nationwide, had been treated with TCM. Clinical observation showed that the 'Three Medicines and Three Medical Formulas' approved

\footnotetext{
16 https://www.nytimes.com/2020/08/24/health/coronavirus-reinf ection.html.

17 https://www.bbc.com/news/world-54082192.

18 https://www.npr.org/sections/health-shots/2020/09/12/91198 7987/a-COVID-19-vaccine-may-be-only-50-effective-is-that-goodenough.
}

by the state had an overall effective rate of over $90 \%$ in relieving symptoms, preventing mild and common cases from developing into severe cases, improving the recovery rate and reducing fatality rate, and boosting the recovery of patients during their rehabilitation process. ${ }^{19}$ For example, from early February to mid April, 2020, around 390,000 packs of 'Lung Cleansing and Detoxifying Decoction', the first TCM formula for nationwide application, was locally produced and distributed to hospitals and quarantine places in Wuhan city, and 500,000 granule packs was produced for the whole Hubei Province, all for free distribution with the costs covered by the government. ${ }^{20}$

According to official statistics, as of 31 May 2020, the average expense for treating by western medicine of a confirmed patient was RMB 23,000 (around USD 3380), and for a severe case RMB 150,000 (around USD 22,000). ${ }^{21}$ In contrast, one course of treatment of three days with 'Lung Cleansing and Detoxifying Decoction' cost only RMB 100 (around USD 14.8). ${ }^{22}$ The questions that need to be asked are: firstly, are the claims of effective TCM credible and clinically proven? What are the criteria to evaluate its effectiveness? Secondly, if TCM is indeed effective, would this help lift TCM from its subjugated position for a whole century in China? Without examining the history of its subjugation, the mechanisms of the subjugation, as well as the institutional, philosophical, methodological and cultural processes of the subjugation, talk about general recognition or rejuvenation of TCM can only be superficial and illusory.

\section{Millenary Tradition Gone Under in One Century}

The starting point is to see that whatever their different 'effectiveness', western medicine and TCM belong to two parallel, if not opposite, philosophies, approaches and treatment methods. TCM has had a history of, some say, 8000-10,000 years in China. Body dissection parts and names of diseases were recorded on oracle bones dating back to 3500 years ago. The first medical classic was Huangdi Neijing (Inner Classics of Yellow Emperor), estimated to

\footnotetext{
${ }^{19}$ State Council Information Office Briefing on TCM's Important Role and a List of Effective Drugs in COVID-19 Prevention and Control, 25 March 2020, http://english.scio.gov.cn/pressroom/202003/25/content_75858152.htm.

20 http://www.gov.cn/xinwen/gwylflkjz95/index.htm.

${ }^{21}$ Fighting COVID-19 China in Action, The State Council Information Office of the People's Republic of China, June 2020, https:// language.chinadaily.com.cn/a/202006/08/WS5edde063a310834817 251871.html.

22 http://www.gov.cn/xinwen/2020-04/12/content_5501508.htm; http://www.gov.cn/xinwen/gwylflkjz95/index.htm.
} 
be compiled between 475 and 206 b.c. Another classic of 450 years ago is the Compendium of Materia Medica (Li 2003), considered the most comprehensive classic with details of herbs and animal parts for medicinal use. There are thousands of medical books and manuscripts on TCM. However, within a century, TCM has gone under. Its significance gains recognition only when alternative treatments and therapies are being sought today to fight COVID-19.

There are external and internal factors contributing to the going under of TCM with the introduction of western medicine. Culturally, the 'West' was seen as superior after its military victories in China since the mid-nineteenth century, starting with the Opium War. China's modernization process was embraced by intellectuals studying in Japan, US and Europe. In the 1920s, the Rockefeller Foundation made moves into China. As recounted by Hans Ruesch, 'Rockefeller had always had a particular interest in China, where Standard Oil was almost the sole supplier of kerosene and oil 'for the lamps of China'. So he put money to establish the China Medical Board and to build the Peking Union Medical College, playing the role of the Great White Father who has come to dispense knowledge on his lowly children. The Rockefeller Foundation invested up to $\$ 45,000,000$ into 'westernizing' (actually corrupting) Chinese medicine' (Ruesch 1993). E. Richard Brown wrote: 'In China, as throughout the world, the Rockefeller philanthropists soon concluded that medicine and public health by themselves were far more effective than either missionaries or armies in pursuing the same ends. In China, the Rockefeller Foundation removed the Peking Union Medical College from missionary society control and established it under Foundation direction. In China, the Philippines, Latin America, the West Indies, Ceylon and Malaya, Egypt, and other countries, the Rockefeller Foundation's International Health Commission organized, financed, and directed major campaigns against the hookworm... The indigenous governments were seen largely as vehicles for a penetrating political, economic, and cultural control by U.S. corporations and agencies. In China, for example, the Rockefeller Foundation's Peking Union Medical College (PUMC) was conducted entirely by their own staff from New York and a local office in Peking... Acceptance of European and American medical theories and practice implied submission to the authority and superiority of these foreign cultures' (Brown 1976).

From the 1920s to 1949 , under the Kuomintang government, TCM was systematically repressed through administrative measures. In 1928, Liu Ruiheng, former dean of Peking Union Medical College and former director of Chinese Medical Association, became the vice-minister of Ministry of Health. In 1929, Liu moderated the first meeting of the Central Committee of Health, in which the Ordinance of the Abolition of Traditional Chinese Medicine was passed. All committee members were non TCM practitioners.
When the Communist Party of China took power in 1949, the Rockefeller Foundation shifted its focus to Japan, India and Latin America. However, the hegemony of western medicine prevailed in China. It was not until 1980 that the Ministry of Health convened a conference and stated that TCM, western medicine, and integration of TCM and western medicine, were three different areas which should be developed in co-existence. In 1986, the National Administration of Traditional Chinese Medicine was established. However, it has been administratively under the control of the Ministry of Health, hence lacking its autonomy, and the Ministry of Health comprised mostly of Western medical personnel.

In 2007-2017, average funding for TCM accounted for less than $10 \%$ of the national medical fund, and it came down to $6.25 \%$ in 2017 (Chen et al. 2020). The number of western medicine practitioners increased from 20,000 in 1950 to 1.57 million in 2004, an increase of 70 times; in contrast, TCM practitioners were 270,000-300,000 in 1950, and 270,000 in 2004 (Lü 2006). In 2017, of the total number of medical practitioners of $8,978,230$, only 663,557 (7.39\%) were TCM practitioners. Of the 34,354 hospitals, only 5232 (15.2\%) were TCM hospitals. Patients consulting medical practitioners was 8.72 billion, of which 1.16 billion (13.3\%) consulted TCM practitioners (Chen et al. 2020).

It is not simply the question of funding or the number of medical doctors, hospitals and medical students that has put TCM at a grave disadvantage. The problem is the refusal to respect or recognize TCM as a different system which has its own history, philosophy, approach and methodology. By subordinating TCM to the validation criteria and management regulation of western medicine, the soul and backbone of TCM are assassinated. In 1999 the promulgation of the Law on Practicing Doctors in China rendered many grassroots TCM doctors illegal. It was reported that over 50,000 practitioners without certificates were banned in 2004, and a further 34,000 banned before July 2005 (Lü 2006).

\section{In the Name of 'Science'}

Hence, TCM has been domestically subdued, and the subjugation is not only to western medicine within China, but to Western medicine hegemonic in the West. The United States FDA has become the supreme adjudicator, deciding what is and what is not to be approved. One example is Lianhua Qingwen Capsule that was proven effective especially when early symptoms of COVID-19 developed. Lianhua Qingwen Capsule drew anti-pandemic formulas from traditional TCM classics: Treatise on Cold Damage Disorders, by Zhang Zhongjing, AD 200-210; A Treatise on Epidemic, by Wu Youke, 1642; Analysis of Pestilential Febrile Diseases, 
by Wu Jutong, $1798 .^{23}$ After the SARS outbreak in 2003, the capsule was developed by Wu Yiling from the Chinese Academy of Engineering. Wu estimated from the sale of the Capsule since the COVID-19 outbreak that up to 21 August 2020, 80 million person times had taken Lianhua Qingwen prescriptions. ${ }^{24}$

Yet, how has been the promotion of this medicine abroad? Early in 2015, it entered phase II of clinical trial of the US FDA, and there has not been further progress. Europe continues to carry out strict regulations on it, and it is banned from clinical trials in hospitals. ${ }^{25}$ Today, Lianhua Qingwen Capsule is registered in only six countries: Canada, Brazil, Romania, Thailand, Indonesia, and Mozambique, under various labels such as Chinese patent drug, natural health food, or food supplement. ${ }^{26}$ In contrast, in 2020, the US FDA approved an impressive number of 1171 generics, breaking its previous record of 971 in $2018 .{ }^{27}$

It is indeed a new development when COVID-19 unveils the grave inadequacies of western medicine. In China, the government has come out to highlight the significance of TCM theories, clinical practices, prescriptions, medications and medical techniques for the prevention and treatment of infectious diseases: 'TCM is a treasure of ancient Chinese science, and a form of holistic medicine that covers prevention, treatment and rehabilitation of illnesses. It enjoys a history dating back to antiquity and extensive popularity among Chinese households. Whenever a serious epidemic has broken out, we have always found suitable solutions using TCM treatment'. ${ }^{28}$

Traditional medicine is not unique to China. In many ancient civilizations, be it in India, Africa or the Amazon, there have been long-standing traditions. Their fate is similar to TCM. Their subjugation is imposed by the powerful hegemony of the theories, practice and methodology of western medicine. What is involved is not only a belief system in western medicine, but enormous interests of transnational pharmaceutical corporations. In 2019, the global pharmaceutical industry continued to grow at a rapid pace, making an estimated USD1.3 trillion. The lucrative profit was shared by the top ten transnational pharmaceutical corporations, from the US, Europe, and Japan, i.e. Roche, Pfizer, Johnson
\& Johnson, Merck, Novartis, Abbvie, Takeda, Bristol-Myers Squibb, Sanofi, and Amgen. ${ }^{29}$

On May 25, 2019, the World Health Assembly, the governing body of WHO, formally approved its influential global compendium, known as the International Classification of Diseases 11th Revision: The global standard for diagnostic health information, or ICD, which included a chapter on traditional medicine (TM) for the first time. ${ }^{30}$

WHO said that the "purpose of the ICD is to capture information on all health conditions and their treatmentthe reason for including traditional medicine conditions and practices is that it is used by hundreds of thousands of people worldwide'. Tarik Jasarevic, WHO spokesman, stressed that the inclusion of traditional medicine diagnosis in the ICD would 'link traditional medicine practices with global norms and standard development', and it was 'not an endorsement of the scientific validity of any Traditional Medicine practice or the efficacy of any Traditional Medicine intervention'. ${ }^{31}$

WHO's modest inclusion of TM drew much controversial criticism. The editorial of Scientific American magazine criticized that 'To include TCM in the ICD is an egregious lapse in evidence-based thinking and practice', and they urged for its removal: 'until they undergo rigorous testing for purity, efficacy, dosage and safety, the WHO should remove traditional medicines from its list'. ${ }^{32}$ The editorial of Nature warned that 'the World Health Organization's decision to include traditional Chinese medicine in its global diagnostic compendium could backfire', and criticized that 'TCM is based on unsubstantiated theories about meridians and qi. Most Western-trained doctors and medical researchers regard TCM practices with scepticism: there is no firm evidence that most of them work, and some signs that a few do harm, ${ }^{33}$

\section{Decolonizing the Global Medicinal Regime is on the Agenda}

In the face of COVID-19 in Africa, on 4 May 2020, WHO issued a statement affirming TM in Africa: 'WHO recognizes that traditional, complementary and alternative

\footnotetext{
23 http://www.fjxiehe.com/yxzc/yxkp/202002/t20200225_9557.htm.

24 https://www.thepaper.cn/newsDetail_forward_8822748.

25 https://www.huxiu.com/article/351989.html.

26 https://www.huxiu.com/article/351989.html.

27 https://www.proclinical.com/blogs/2020-8/the-top-10-pharmaceut ical-companies-in-the-world-2020.

28 State Council Information Office Briefing on TCM's Important Role and a List of Effective Drugs in COVID-19 Prevention and Control, 25 March 2020, see http://english.scio.gov.cn/pressroom/202003/25/content_75858152.htm.
}

\footnotetext{
29 https://www.proclinical.com/blogs/2020-8/the-top-10-pharmaceut ical-companies-in-the-world-2020.

30 https://icd.who.int/icd11 refguide/en/index.html\#1.5Traditionalmed icineltraditional-medicinelc1-5.

31 https://edition.cnn.com/2019/05/24/health/traditional-chinesemedicine-who-controversy-intl/index.html.

32 https://www.scientificamerican.com/article/the-world-health-organ ization-gives-the-nod-to-traditional-chinese-medicine-bad-idea/.

33 https://www.nature.com/articles/d41586-019-01726-1.
} 
medicine has many benefits and Africa has a long history of traditional medicine and practitioners that play an important role in providing care to populations. Medicinal plants such as Artemisia Annua are being considered as possible treatments for COVID-19 and should be tested for efficacy and adverse side effects. Africans deserve to use medicines tested to the same standards as people in the rest of the world. Even if therapies are derived from traditional practice and natural, establishing their efficacy and safety through rigorous clinical trials is critical... Over the past two decades, WHO has been working with countries to ensure safe and effective traditional medicine development in Africa by providing financial resources and technical support. WHO has supported clinical trials, leading 14 countries to issue marketing authorization for 89 traditional medicine products which have met international and national requirements for registration. Of these, 43 have been included in national essential medicines lists. ${ }^{34}$

This statement shows once again the same kind of impositions on TM everywhere, the stress on 'scientifically proven' medicines wherein western Science is supreme. When the statement says 'Africans deserve to use medicines tested to the same standards as people in the rest of the world', the apparent granting of 'equal rights' to Africans is de facto denying them of TM (not tested to the 'same standards') that could save their lives and improve their well-being; the killer is the application of the so-called 'same standards'. While somehow the long history of TM in Africa is vaguely recognized, TM is required to undergo clinical trials as designated by western medicine. The marketing authorization of $89 \mathrm{TM}$ products in 20 years, in 14 countries, speaks of the pathetic state, though presented here as an achievement. Better than none, and it is indeed an immense achievement for those taking on this uphill task. Up till now, WHO still refuses to recognize the role of Artemisia Annua in the fight against malaria according to antimalarial traditional medicine practices in Africa. Katharina Weingartner's documentary, The Fever, presents the story to us. On the other hand, the entire R\&D portfolio on malaria is now in the hands of the Bill \& Melinda Gates Foundation. The role of so-called philanthropist foundations in sponsoring or commanding research, production and promotion of certain medicines while repressing or subjugating others need to be scrutinized. Whether it be Rockefeller Foundation, Bill \& Melinda Gates Foundation, Wellcome Trust, or others.

In order to meet the same regulatory standard imposed by the FDA or its likes, probably we will need to apply dozens

\footnotetext{
34 https://www.afro.who.int/news/who-supports-scientifically-prove n-traditional-medicine?gclid=CjwKCAjwzIH7BRAbEiwAoDxxT rZY8LBlIg8NP0ubr27BlzCe901DQLrUexpF0yawZMoscWGdtcH JJRoCpvYQAvD_BwE.
}

of needles on a poor little guinea pig to seek evidence of the effectiveness of Chinese acupuncture.

Not even Tu Youyou's award of Nobel Prize in Physiology or Medicine in 2015 could add much weight to TCM. From the account of her story, we can see how she has worked on TCM in her research, and discovered artemisinin for treating millions of malaria patients. ${ }^{35}$ Yet, Nobel committee member Hans Forssberg reiterated: 'It's very important that we are not giving a prize to traditional medicine, the award was only for scientific work that had been inspired by it'. ${ }^{36}$

It is another long story as to the patenting of artemisinin, and how it has fallen from Chinese hands to the grip of foreign pharmaceutical transnationals. So many stories are still untold, but none is a surprise if we can see into the operation of the immensely lucrative and monopolistic business of pharmaceuticals. TikTok editions are plenty.

TCM or TM everywhere have baskets of problems to handle. It is not as if western medicine is problematic or inadequate, that TM becomes the golden recipe. Not only is there a question of heritage - of nurturing medical practitioners to take on the lineage, there is also a major devastation and disappearing of traditional herbal plants under rapid urbanization, massive deforestation, and raging climate change.

We would like to stress that: when 'scientifically-proven' is the magic sword waged by the US FDA and hegemons of western medicine, the alternative is not resorting to 'antiscience', but an interrogation of how the entire concept of 'Science' has become monolithic, upheld by the military and monetary muscles of the Western powers, so that the universalistic idea of Science comes to refer only to Eurocentric theories and practices, negating and demonizing other long-standing theories and practices. What also need to be interrogated is the approach and methodology of modern science. The way Albert Howard or Wendell Berry, pioneers in organic agriculture and environmental science, discuss plant diseases can illuminate the way we look at human diseases. They observe 'a wide chasm between science in the laboratory and practice in the field'. The effort should be to bridge this gap, and 'the way to do it was simply to refuse to see anything in isolation. Everything... existed within a context, outside of which it was unintelligible. Moreover, every problem existed within a context, outside of which it was unsolvable... If nothing exists in isolation, then all problems are circumstantial; no problem resides, or can be solved, in anybody's department. A disease was, thus, a symptom of a larger disorder' (Berry 2006). Research need to be integral and not fragmented. Alas! This is precisely the problem of so-called 'scientific' research in the laboratory of modern medicine.

\footnotetext{
35 https://www.nobelprize.org/prizes/medicine/2015/tu/facts/.

36 https://www.ncbi.nlm.nih.gov/pmc/articles/PMC4728866/.
} 
To counter the stress on 'scientifically-proven', drawing on long traditions of diverse civilizations, we should acknowledge the wisdoms of the 'culturally-proven', putting problems and solutions in context. When, one day, profitmaking is removed from essential medicines, when food and fresh water is guaranteed for all humans on earth, when diverse cultures gain genuine recognition and respect, we can together swim.

\section{References}

Berry, Wendell. 2006. "New introduction" to The Soil and Health, by Sir Albert Howard, Lexington: University of Kentucky Press: xviii-xix.
Brown, E. Richard. 1976. Public Health in Imperialism: Early Rockefeller Programs at Home and Abroad, https://doi.org/10.2105/ AJPH.66.9.897

Chen, Zuozuo, Xueying Li, Jianzuo Guo, and Yanbin Hu. 2020. Reviews on The Policy Change and Responds of Traditional Chinese Medicine for 70th Anniversary of New China. Asia-Pacific Traditional Medicine 16 (3): 3-11.

Li, Shizhen. 2003. Compendium of Materia Medica: Bencao Gangmu. Beijing: Foreign Languages Press.

Lü, Jiage. 2006. Rescuing Traditional Chinese Medicine: how TCM falls in the Institutional Trap and Capitalist Conspiracy. Guilin: Guangxi Normal University Press.

Ruesch, Hans. 1993. The Truth about the Rockefeller Drug Empire: The Drug Story. www.healingcancernaturally.com/rockefelle r-drug-empire-story.html

Publisher's Note Springer Nature remains neutral with regard to jurisdictional claims in published maps and institutional affiliations. 